\title{
The School Management Team Leadership Role in Rural Primary School Setting
}

\author{
${ }^{1}$ Mathipa Elias \\ ${ }^{2}$ Magano Meahabo Dinah \\ 3Mapotse Tome \\ ${ }^{4}$ Matlabe Sizakele \\ 5Mohapi Soane \\ ${ }^{2}$ Department of Inclusive Education, University of South Africa, PO Box 392,Pretoria, 0003, South Africa \\ Email:maganmd@unisa.ac.za \\ ${ }^{3}$ Department of Science and Technology, University of South Africa \\ 1\& 4Department of ABET and Youth Development, University of South Africa \\ ${ }^{5}$ Centre for Teacher In-Service Education and Training, University of South Africa
}

Doi:10.5901/mjss.2014.v5n7p367

\section{Abstract}

The School Management Team (SMT) as constituted in the new educational dispensation that ushered in the Outcome Basic Education System (OBE) is a new structure with the sole function of giving leadership guidance, direction and assistance in the teaching/learning situation. In this paper we deliberately sought to understand how the STM in a rural school environment exercises its leadership role. We followed the qualitative approach with an interview schedule which was prepared by the Unisa's College of Education for use by all the teams that were dispatched to the 500 schools the Basic Education Department had targeted for this project. Rural schools are terribly challenged because it is trite fact that they lack the requisite facilities for education to take place unhindered and also optimally. For the SMT to be effective they are expected to be able to improvise by way of creating the much needed teaching/learning aids/materials that will ensure that the educative activity takes place effectively. In our research project we actually looked for anything that could dramatically convince us that the SMT was innovative and creative enough to initiate inviting teaching/learning environments that make learners to enjoy and participate in the lesson. What we found was not discouraging but needed some improvement here and there especially that the SMT was made of people who are ready to learn. Our intention is to go back to the school and give a hand of assistance in the areas we have identified as in need of further strengthening and development.

Keywords: School Management team, rural, primary school, learner performance

\section{Introduction}

Our point of entry and departure was succinctly and concisely described to us by the Basic Education Department in its guide that contained seven questions which we were to use when interviewing the School Management Team. In addition, all the teams that were dispatched to the 500 schools in the five Identified provinces were meticulously selected and also given appropriate training in how to conduct the various interviews involving: teachers, learners, parents and the School Management Team. The teams were given training in conducting interviews and also how to take notes, photos of participants, make observations as well to write reports. This paper is an outcome of a visit to one rural school that acted as our case study in this instance.

In his arguments about the question of: 'what are schools for?' Ebel (1974:5) instructively and compellingly posits the view that:

- Schools are not custodial institutions responsible for coping with emotionally disturbed or incorrigible young people, for keeping nonstudents off the streets or out of the job market;

- Schools are not adjustment centres, responsible for helping young people develop favourable self-concepts, solve personal problems, and come to terms with life; 
- Schools are not recreational facilities designed to entertain and amuse, to cultivate the enjoyment of freedom, to help young people strength through joy; finally

- Schools are not social research agencies, to which a society can properly delegate responsibility for the discovery of solutions to the problems that are currently troubling the society."

Where do we stand in this contested terrain as stakeholders; especially as universities which have the necessary capacity to engage, interrogate and also research educational matters? Our strong belief is that the SMT is the driving force in the school situation and as such must give sound leadership direction; this is in our humble opinion, and is based on the view that managing school activities is part and parcel of the SMT's core function.

\section{Literature Review}

To begin with, in the Government Gazette of 02/August/2010 the Minister of Basic Education Mrs. A Motshekga unveiled an action plan called Action Plan to 2014 containing 27 national goals aimed at bringing about "...better school results and better enrolment of learners in schools." Whereas the former Minister of Education and Training Mrs. Pandor in the Government Gazette of 26/April/2007:09 said that the policy framework she was introducing aimed at the provision of:

- Teachers who are properly equipped to undertake their essential and demanding tasks;

- Teachers who are able to continually enhance their professional competence and performance;

- Appropriately qualified teachers to fill all vacancies in all schools, and that there is a dynamic balance between demand and supply of teachers; and that;

- There is a community of competent teachers dedicated to providing education of high quality, with high levels of performance as well as ethical and professional standards of conduct;

- Finally, that the teachers are deservedly held in high regard by the people of South Africa."

All the above view-points should be seen in the light of the failures of the system of Outcome Based Education which is known for its particular emphasis on learner performance as a barometer to measure achievement. To put the issue in perspective, the Annual National Assessment (ANA) learner performance on a national scale was used to assess Grades 3 and 6 and to say the least, the results of the learners are shocking particularly in the following learning areas: Home Language, First Language, Natural Science \& Technology and Mathematics. This present paper is concerned with what Kallaway (2009) has described as: the crisis that has been predicted by many experienced professionals ever since the early nineties appears to have finally arrived as poor learner performance has reached tragic proportions; and the nation has to face the real prospects of a 'lost generation' of a magnitude it has experienced in the past.

\section{The Purpose of the Paper}

The purpose of this paper is to determine the precise leadership role that is played by the school management team in creating a conducive teaching/learning environment in a rural primary school setting. The issue of poor performance by learners has been for a considerable time been under the microscope of different researchers who went on to attribute it to a variety of causes such as learners' social and economic circumstances (Legotlo, Maaga \& Sebego, 2002; Simkins \& Paterson, 2005); lack of learner support materials and related resources (Legotlo \& Van der Westhuizen, 1996; Legotlo, Maaga \& Sebego, 2002); overcrowding; lack of teachers' and learners' discipline and commitment, to mention but a few. Indeed poor learner performance has shocked the nation because it has become a serious indictment on the most praised system of education (OBE) that lays a heavy emphasis on learner performance as the ultimate goal.

\section{The Statement of the Problem}

The problem this research study dealt with is that of trying to find out what is actually entailed in the leadership role of the SMT in a rural primary school setting.

To avoid dealing with many issues of the school management team leadership role in rural primary school setting. It is worth noting that the SMT is a vital organ of the school that must produce is strategic management plan of the school for the purposes of functioning in an orderly fashion.

\section{The Conceptual Framework for the Paper}

This paper is framed around the following humanitarian concepts: physical capacity; personality and talent; adequate training; job satisfaction and productivity standards/levels. Opportunities should be created through models, practices or 
experiences of teacher education that would allow practicing educators in the rural schools to be given regular workshops by experienced and expert lecturers. This should be done in order to:

- Empower the educators in the latest approaches, methods, techniques and knowledge content so they can teach effectively and with confidence;

And

- To enlarge the educators' outlook and understanding of their professional needs.

There are forces at work that challenge the educators in the form of rapidly increasing knowledge and technology; increasing the need for teachers to specialise in teaching subjects that they feel confident to handle. A teacher must be well grounded content wise. Therefore, the current teaching ought to demand teachers who are versatile and also flexible so they can be able to improvise and also initiate creative ways of imparting knowledge and skills. Carl (1995:11) is of the opinion that "teachers must realise that they themselves have a specific role to play in a self-empowerment process." In this context, whatever Unisa is intending to do at the school level through workshops/seminars aimed at empowering and capacitating those educators doing service especially in the rural schools; will only succeed if educators themselves play a significant role.

\section{The Theoretical Framework of this Paper}

This paper is framed around the systems theory which argues that "no entity of any description whatsoever can be understood properly unless we take into account its total system" (Higgs \& Smith 2002:27). The SMT is part and parcel of the school system and its management role and functions can only be understood within the school situation. Management is a process of organizing and utilizing both human and material resources to achieve predetermined goals. In other words, it is within the school system that the SMT is expected to play a leading role in as far as giving guidance, advice, support, help and leadership to the entire management needs the school. Such leadership should be of a type that is strategically sound and accountable.

There are various kinds of leadership styles each with its own theory of what leadership is, and how it ought to function in order to achieve its goal. To hit the keynote Jenkins (1991:25) points out that "the concept of organizational culture has become an increasing focus for studies in educational management." To crown it all Glatter et al (1988:106) simply says that "a school culture is the pattern of beliefs and expectations of the members of the school community that guide their predominant attitudes and behaviours." Therefore, it goes without much ado that each school has to create and also design its own teaching/learning culture with a unique environment. Otherwise, it will be boring and unchallenging to try and replicate or copy what others are doing in their own unique teaching/learning cultural environments and apply to one's school. The following cultural leadership theories are distinguished in this paper and they are:

\subsection{Power Culture}

Briefly, leaders imbued with the power culture spirit demands performance from the followers and show little concern to their wellbeing. Handy (1988:86) describes this type of power culture as representing "a spider's web, because the key to the whole organization sits in the centre, surrounded by ever widening circles of intimates and influence." In this structure the principal is the key person and everything revolves around him/her. The principal is the school and everything else exists to extend his/her interests and influence. In fact this describes definitively the type of leadership know as authoritative or autocratic.

According to Harrison (1987:8) that disadvantage is that "... the boss's resources are overused and everyone else's resources are underused. People do what they are told; when they aren't told, hey try to guess what the boss would want them to do and when they aren't sure, they wait." When we interacted with the SMT we were conscious of this fact.

\subsection{Role Culture}

Handy (1988:104) describes role culture as depicting "a Greek temple whose patron is Apollo the god of reason." This role culture resembles a pyramid of boxes containing different jobs with individuals names of staff members attached to each box. The individual members of staff have their role well defined in that their duties are clearly stated; they are given clear guidelines and rules of how they should carry-out their functions and are in the end rewarded according to their performances. In this type of role culture the individual staff members are consulted and also given opportunity to state 
their point of view or allowed to contribute. This is a democratic style of leadership or what is also called consultative style of leadership.

Harrison (1988:8) again points out that "... the trouble with role-oriented organization is that it overuses the talents and personal energies of designers and underuses those of doers. Much management ingenuity and creativity go into the design and development of structures and systems, which then limit and frustrate the ingenuity and initiative of the people who are charges with performing the work."

\subsection{Task Culture}

The task culture is defined by Handy (1988), Lee et al. (1988) and Saunders (1984) "as it put people and resources together and let them get on with particular tasks. It is a team culture whereby hierarchy is minimal and people are evaluated on the basis of their ability to contribute to the team's success." This type culture of leadership is also known as achievement culture or participative culture. This kind of culture generates a warm environment whose spin-offs are good human-relationships. Such a type of leadership is referred to as the delegate type of leadership.

According to Denison (1984:19) in this type of culture "workers become more "hired-hands" and develop a sense of ownership over their efforts within the organisations to the work place. An environment is created that requires an organization's members to become psychologically involved and to become aware of and concerned with the consequences of their actions."

\subsection{Person Culture}

In the opinion of Kilmann et al (1985:104) this type of culture "exhibits a high concern for the wellbeing of his people, but does not impose very high standards of performance on them. This kind of culture is usually an expression of the "paternalistic philosophy of the organisation's founders or key leadership." It is a kind of leadership culture commonly called facilitative type.

According to Harrison (1987:7) a person is identified by the following characteristics:

$>$ The members of the school community help each other beyond formal demands of their jobs;

$>$ Members communicate a great deal, not only about their job environment, but also about personal concerns;

$>$ Members like spending time together;

$>$ Staff celebrate together; and

$>$ Staff value harmony and avoid confrontation.

The above discussed leadership cultures' principles and criteria will be used to evaluate the duties, functions and roles of the SMT's in the context of a rural school setting or environment.

\section{The Methodology of Accountability}

The study is embedded within an interpretivist paradigm that is based on the systematic review approach which states that "systematic reviews are best suitable for focused topics" (Collins and Fauser 2005:12). The interpretivist paradigm is very flexible as it allows the researchers to utilise a variety of perspectives and methods like: the transformative, critical and constructive perspectives and also offers

In other words, the study's approach was basically a qualitative one and was framed around a case study which focused attention an individual who was purposively identified. With the help of this individual, the study further identified one individual through the snow-balling technique. Henning et al (2004) defines a case study as a means of exploring and understanding the groups or individuals ascribed to a social or human problem. We used the qualitative research method because we were interested in getting an in-depth knowledge about the educators who teach at adult center's following guidelines highlighted by Schumacher and MacMillan (1997).

The members of the SMT were given confidentiality forms to sign after everything was explained to them. They were also informed that their participation was voluntary and that they had the right to withdraw at any time they felt they were no longer interest or willing to participate in the interview. They were told that their identities would be kept anonymous. The SMT consist of only the principal and the HOD. The participants were requested to indicate whether they agree to take photos and to be tape recorded and they agreed. 


\section{The Given Questions are Captured Below}

$>$ What kinds of roles are you expected to play in the management of your school?

$>$ Do you feel that you can perform these roles as expected?

$>$ What are some challenges you face in performing these duties?

$>$ What strategies do you use to improve student learning?

$>$ What do you think is needed to improve this?

$>$ Who might be able to help to provide assistance?

$>$ What is the ideal situation you would like for your school in future?

What do you think is mainly needed in order to get there?

The answers to these questions constituted the research findings which were classified into categories that culminated in the formation of the following themes:

A theme on administration came out clearly when the members of SMT responded to the first question by stating that:

1. They do their entire planning by organising all activities involving teaching/learning and the extra-curriculum in a year programme; to this end Zeichner (1991:365) is of the view that "teachers must be allowed to make their own decisions in regard to subject-related aspects; and also in regard to curricula and organisational aspects falling outside their particular classrooms." According to Harrison (1987:7) the members of the school community should help each other beyond formal demands of their jobs and they should communicate a great deal, not only about their job environment, but also about personal concerns, and they could do so by spending time together, celebrate together and value harmony and avoid confrontation. Finally, Steyn (2012:252) adds by stating that "all programmes in the school, both curricular and extracurricular, should work for the benefit of everybody in the school."

2. The strategy use by the SMT is of liaising with staff on issues relevant to their teaching requirements and they discuss the school needs in meetings of the School Governing Body (SGB) and thereafter involve the circuit office; this a good thing because Kelly as quoted by Salmon (1995:8) complements by saying "the world is open to an infinite number of constructions, and many of the best ones have yet to be devised."

3. The STM makes sure that it communicates with staff, parents, learners and circuit officials so as to ensure that there is proper cooperation, teamwork, coordination and control of all activities taking place in the school. To sum up, there are 16 teachers and 467 learners and this makes the teacher-learner ratio to be normal and acceptable but the main problem is that at the lower grades two teachers teach separate groups in one classroom. This is worse than overcrowding which is a problem that prevails in some of the higher grades. A situation such as this one creates a difficult teaching environment because it produces a climate that is demotivating and is clearly against good teaching practices and experiences.

A theme on resources and facilities was the second which received the SMT's attention and their response is:

1. The school lacks resources and mentioned things like: computers, books, stationary, and chemicals for doing experiments, chairs and tables. The role of resources in the education occurrence cannot be underestimated because without the necessary resources not much will be achieved. An army that goes to war without the weapons cannot hope to win.

2. The school has a shortage of facilities like: classes, toilets, library, laboratory, offices and a school hall. Parents tried to contribute money to build an extra classroom but without success because the Department of Education against parents paying for anything in the schools of this category. How on earth can parents be denied to take responsibility of their children's education; and Salmon (1995:10) advices by pointing out that "a model of education which accords the highest value to human questioning must necessarily view learning and teaching in process rather than in product terms." Education must make people think and question issues, but how can people think when they are denied the opportunity to solve their own problems?

A theme on learner behaviour reveals that:

1. Learners according to SMT are not involved in gangsterism. The SMT also pointed out that the school is not experiencing bullying, stealing or use of drugs. But when we had a session with the learners they emphatically indicated that there are some elements of bullying in the school. Childhood is a time of experimenting and it often lands children in trouble.

2. The SMT said the school is having no child-headed families, but they think there may be one family that is affected; this can be due to parents working far away in the cities as the school is in a rural area where there 
are employment opportunities; or it might be as a result of parents having died because of the HIVIAIDS pandemic.

3. According to the SMT the learners are willing to attend extra classes but they are prevented to do so by pressure exert by poor transport system which makes it is difficult for the school to function smoothly because the available transport is irregular and as such it fails to ferry learners and teachers to and from school at the right time. Gould (1993:100) is compelling when arguing that "the range of a school can also be extended with improved availability of and access to public or private transport, to allow great distances to be covered in the same period of time taken o walk to school."

4. The SMT said learners move in groups when going home so that they can deter would be rapists and or murderers. Lack of safety to learners and teachers at school and the surroundings has potential to affect the smooth running of the programme of the school in many ways including the time to start the school day and end it. Safety and security constitute basic human needs because human beings yearn and also hanker after a sense of certainty.

A theme on teacher professional growth and development indicates that:

1. According to the SMT the teacher unions have taken the position that teachers will not attend any workshops during weekends or after working hours. In other words, teachers would only attend workshops that are conducted during teaching time when they are needed in classroom, otherwise they will not cooperate. Carl $(199: 2)$ is instructive when saying "each teacher must be systematically empowered in regard to curriculum development, to optimise the teaching-learning events in the classroom." The question is how will teacher empowerment happen when teachers themselves through their own unions are making matters difficult if not impossible?

2. The SMT revealed that the University of Witwatersrand has been helping the science learners to master their subjects and this has been successful because the science learners are doing well. Wits University is doing this outreach programme through a lecturer who is himself the son of the soil and had attended his primary education at this school. However, the teachers themselves need to professionally and academically grow and develop so they can keep abreast with developments in their profession, because 'an empowered teacher is pre-eminently able to develop pupils' potential optimally" (Carl 1995:2).

Their suggested strategies to improve the situation are:

- The SMT think that it will be good if the parents could contribute towards the building of extra classrooms so as to manage overcrowding because currently certain classrooms accommodate large numbers that can be divided into two classrooms. This type of a teaching/learning situation is certainly not ideal for meaningful teaching and also learning. In some instances, two teachers teach in one classroom two different groups of learners who occupy separate corners of a classroom. This to say the least can be regarded an unwinnable situation.

The suggestion that parents contribute to the education of their children makes sense because we are taught that; for six of the seven days of the week our creator toiled to create the universe with all in it and only rested on the seventh day. Everyone shall eat from the sweat of his brow. Therefore, people should be taught that there is nothing for nothing.

- The need for extra teaching posts is not sustainable because the teacher/learner ratio does not warrant it. Presently, classrooms are sorely needed for those teachers without accommodation to be able to express themselves in their own classrooms, even though the SMT felt that they needed more teachers to run the school more effectively. The SMT should be taught to prioritise.

- The matter of extra classrooms cannot be gainsaid because of the fact that there is overcrowding and also there are incidences where two teachers do their teaching in one classrooms. It is no longer advisable to attend school under trees like in the long past.

- The need for regular monitoring from curriculum implementers who are station in the circuit office was articulated clearly because the curriculum is changed almost every year and teachers are left confused as they are unable to master and consolidated their content-knowledge as a result. Teacher professional growth and development is difficult to realise where the curriculum changes are radical and more often. Teacher growth and development should otherwise be an on-going thing because changes are occurring at all times and affect us in many ways that might be either direct or indirect.

- The misunderstanding that dogs the teacher unions and the Department of Education regarding workshops is hampering staff development and growth both academically and professionally. The few workshops that are being conducted are insufficient and more often than not ineffective. Mathipa (2012:35) points out that 
"nowadays, teachers are needed who can inspire learners to be imaginative, curious, inquisitive, enthusiastic, sincere, motivated and passionate about achieving a bright future for themselves."

- It is a laudable thing to see teachers willing to teach in the afternoon to catch up before Annual National Assessment examinations start. The teaching-staff of this school is doing extra teaching despite the fact that the teacher unions are against doing extra work. Denison (1984:19) argues that in this type of culture employees develop a sense of ownership the organisations and create an environment in which all involved become psychologically committed to achieve the best results.

- The need to see help for the erection of new classrooms is welcome but they school is not going about it more vigorously. The school also not trying hard to talk to the publishers to donate reading books for them. So far Wits University through one of the lecturers who is the son of the soil is helping the science learners do well in the matriculation examination and this collaboration is effective. Other universities in the neighbourhood such as UNISA, Tshwane University of Technology and University of Pretoria could be invited to come and help as well in either staff development or teaching the learners difficult subjects the teachers are not coping well with.

To conclude, "the prominence given to education by individuals, by families, by communities, by national governments and by the international community at large leaves little room for doubting its importance in the Third World" (Gould 1993:1).

\section{References}

Carl, A, E 1993 Teacher Empowerment; through curriculum development Cape Town: Juda \& CO

Collins, P \& Fauser, R 2005 Balancing the strengths of Systematic and Narrative Reviews London: Sage

Denison, D, R. 1984 Bringing COrperative Culture to the Bottom line. Organisational Dynamics 13(2):4-23, autumn

Ebel, R, L. 1974. What are schools for? Contemporary Issues in Educational Pschology Boston: Allyn \& Boston Inc.

Glatter, R, Preedy, M, Riches, C \& Masterton, M. 1988 Understanding School Management Philadelphia Open University Press

Government Gazette of the 2009/April/26

Gould, W, T, S 1993 People and Education in the Third World New York: Iongman

Handy, C. 1988 Understanding Voluntary Organisations London: Penguin

Harrison, R. 1987. Harnessing Personal Energy: How Companies Can Inspire Employees Organisational Dynamics, 15 (1):54-72, autumn.

Henning, E. Gravett, S. \& Van Rensburg, W. 2004. Finding your way in academic writing; Pretoria: Van Schaik.

Higgs, P, \& Smith, J. 2002 Rethinking truth Cape Town: Juta Company LTD

Jenkins, H. O. 1991. Leadership for Tomorrow's Schools London: basil Blackwell

Kilman, R, Saxton, M, J \& Serpa, and R 1985 Gaining Control of the Co-operative Culture San Francisco: Jossey-Bass

Legotlo MW, Maaga MP \& Sebego, MG 2002. Perceptions of Stakeholders on poor performance. South African Journal of Education, 22(2):113-118

Legotlo MW \& Van der Westhuizen PC 1996. Coming on board: Problems facing new principals in developing countries" in Educational management and Administration, 24(4):40-410

Lee, R, \& Lawrence, P. 1988. Organisational Bahaviour: Politics at WOrld. London: Hutchison

Saunders, G. 1984. The Committed Organisation: How to develop companies to compete successfully in the 1990s. Bradford: Gower

Salmon, P. 1995. Psychology in the classroom London: Cassell

Schumacher, S. \& MacMillan, J, H. 1997 Research in education: conceptual introduction. London: Longman.

Simkins, W. \& Paterson, T.2005 Learner Performance in South Africa: Social and economic determinants of success in Language and Mathematics. Cape Town: HSRC Press

Simpson, O. 2008; Motivating learning in open distance learning: do we need a new theory of learner support. Open Learning Vol. 23 No 3 November 2008 pp.159-170.

Steyn, G, M, 2012. Principal Succession in a South African Primary School: impact on invitational education in SAERA Conference Proceedings Cape Town: Digital Press 